\title{
The Use of Bamboo as a Constructive Element. A Proposal from the Catholic University of Santiago de Guayaquil, Ecuador
}

\author{
Jesús Hechavarría*, Robinson Vega, Boris Forero, Rosa Rada, Juan Bamba, Alejandro González and Carlos Donoso \\ Institute of Habitat, Design and Construction, School of Architecture and Design, Catholic University of Santiago de Guayaquil, Ecuador \\ *Corresponding Author: Jesús Hechavarría, Institute of Habitat, Design and Construction, School of Architecture and Design, Catholic \\ University of Santiago de Guayaquil, Ecuador.
}

Received: September 26, 2019; Published: October 31, 2019

DOI: 10.31080/ASAG.2019.03.0708

\begin{abstract}
Agricultural product materials have been traditionally used in the construction of low-income dwellings in Ecuador. One of the most representative is the Bamboo (Guadua Angustifolia Kunth). The Guadua cane as it is also called is used as an element for the construction of scaffoldings or as a construction system like the formation of columns and beams of houses. The Catholic University of Santiago de Guayaquil has a Teaching Unit designed for the fabrication of ecomaterials produced by agriculture. To date, nine intellectual property records have been achieved as a result of the scientific and technical contributions obtained in research projects. Among the registered products are the panels processed with bamboo fibers which are glued with resins and cauterized with industrial presses that allow permanent fixation. The results obtained have been used in several research, development and innovation projects, where they have shown multiple benefits as constructive elements in extreme climates such as Guayaquil City (high temperatures) and Chimborazo volcano (low temperatures). It is currently used in the construction of a low-income housing archetype for inhabitants of Monte Sinahí, at Guayaquil.

The use of ecomaterials in the construction of houses allows reducing the use of materials that contribute to environmental pollution and that require a greater consumption of electrical energy for their production such as: steel, cement and sand, among others. On the other hand, bamboo is one of the plants that absorbs a greater amount of $\mathrm{CO} 2$ during its growth which contributes to the mitigation of climate change. The proper techniques of its harvest after 8 to 10 months, allows its production to be multiplied without having to plant again.

Keywords: Bamboo; Ecomaterials; Low-Income Dwelling; Mitigate Environmental Pollution; Energy Savings
\end{abstract}

\section{Abbreviations}

IEPI: Ecuadorian Institute of Intellectual Property

\section{Introduction}

Global warming caused by greenhouse gases has a negative influence on the environment. Several studies have demonstrated the impact of forest fires in areas as distant as Greenland [1]. The register of high temperatures also represents a great danger in sea level rise due to the decrease of the Antarctic ice sheet [2,3]. That is why we must look for strategies that minimize the environmental impact of greenhouse gas emissions [4]. Energy efficiency is one of the main strategies to mitigate global warming [5]. The use of materials in the housing industry plays a fundamental role in the in thermal comfort of its inhabitants [6,7]. On the other hand, energy saving in the production of materials for housing construction is considered one of the major fields of study to counteract the damage to the environment due to the growing housing deficit that exists in Ecuador [8].

This work provides an opportunity to contribute to the care of the environment through the use of Eco materials as constructive elements at the low-income settlements production [9], in which bioclimatic strategies are applied to reduce electricity consumption due to the use of mechanical ventilation and unnecessary use of lighting during daylight hours [10].

\section{Materials and Methods}

Among the products obtained with ecomaterials, PlasBam stands out. The PlasBam board uses Guadua Angustifolia Kunth as raw material. The manual preparation time of the boards is between 5 to 6 hours and the pressing time does not exceed 25 minutes. Eco-friendly resins, urea 1312 powder and GOMAX 1035 adhesive are used in its manufacture under a vertical pressure of $2.250 \mathrm{~kg} / \mathrm{cm}^{2}$. The following figure shows part of the elaboration process in the Ecomaterial Production Plant of the Catholic University of Santiago de Guayaquil (UCSG in Spanish).

The final product has a flexural strength of 41 to $61 \mathrm{MPa}$ and a compressive strength of 35.61 to $53.65 \mathrm{MPa}$. It can be used as coverings for floors, walls and roofs or as structural elements in: beams, roof armors and columns. 


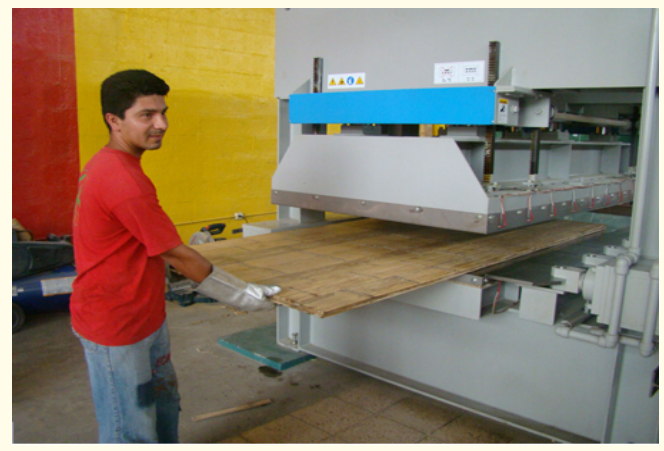

Figure 1: Preparation of PlasBam board at the Ecomaterial Production Plant of the UCSG.

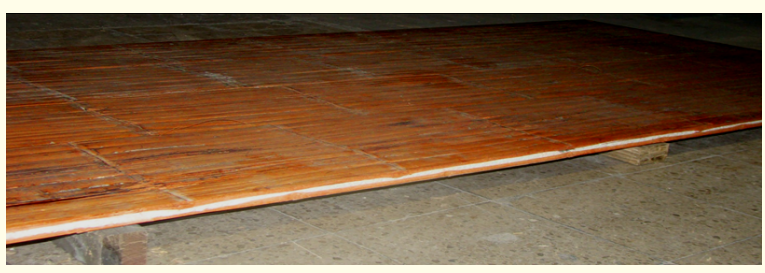

Figure 2: PlasBam board finished.

\section{Results and Discussion}

The research of the multidisciplinary group of ecomaterials of the School of Architecture and Design of the Catholic University of Santiago de Guayaquil has resulted in 9 records of intellectual property in Ecuador.

\begin{tabular}{|c|c|l|c|}
\hline$\#$ & Registry IEPI & \multicolumn{1}{|c|}{ Title } & Code IEPI \\
\hline 1 & $2014-26585$ & Structural boards of Guadua Thermo-Pressed cane (PLAS-BAM) & 01-02-01-2014-01-000282 \\
\hline 2 & $2014-26585$ & Structural boards of Guadua cane open, Thermo-Pressed (ECU-BAM) & $01-02-01-2014-01-000283$ \\
\hline 3 & $2014-26580$ & Cane waste boards (TRIP-BAM) & $01-02-01-2014-01-000279$ \\
\hline 4 & $2014-26583$ & Fireproof product used for coating (REC-BAM) & $01-02-01-2014-01-000281$ \\
\hline 5 & $2014-26581$ & $\begin{array}{l}\text { Procedure to obtain structural boards of open and/or crushed Guadua cane, } \\
\text { thermopress. }\end{array}$ & $01-02-01-2014-01-000280$ \\
\hline 6 & $2014-26598$ & Procedure for obtaining Guadua cane waste boards. & $01-02-01-2014-01-000285$ \\
\hline 7 & $2014-26597$ & Fire retardant plate (PRODUCTO PLAC-CEL) & $01-02-01-2014-01-000284$ \\
\hline 8 & $2014-26596$ & Device for Remove Knots. & $01-02-01-2014-01-000015$ \\
\hline 9 & $2014-26595$ & Device for extraction & $01-02-01-2014-01-000014$ \\
\hline
\end{tabular}

Table 1: Intellectual property records as a result of projects developed.

Among the most relevant results is the research project entitled "Ecuadorian Antarctic Refuge (RAE in Spanish). Development and application of eco-materials in the project and construction of an emergency habitable prototype ", is endorsed by the Institute of Research and Innovation of Habitat, Design and Constructions (IHADIC in Spanish) of the School of Architecture and Design, and financed through the Research and Development System (SINDE in Spanish) of the Catholic University of Santiago de Guayaquil, in collaboration with the Antarctic Ecuadorian National Institute (INAE in Spanish) and the Ministry of Environment of Ecuador (MAE in Spanish). Institutional cooperation as a tool for the activation of project generation processes for the improvement of pre-existing situations, encourages in this research project the participation of the different institutions involved and the exchange of knowledge and knowledge. Figure 3 shows the installation of the Ecuadorian Antarctic Shelter in the Chimborazo volcano (low temperatures) as a partial result of the prototype.

The application of these results is also being used in hot climates such as Guayaquil City (high temperatures) in the construction of a archetype of low-income dwelling for the inhabitants of Monte Sinahí, at Guayaquil, Ecuador.

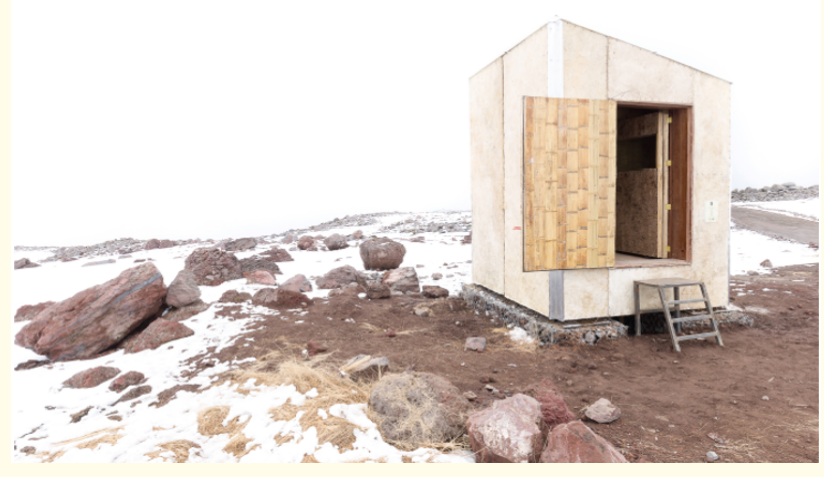

Figure 3: Shelter built in Chimborazo, Ecuador. Source: Bamba and González [11].

\section{Conclusion}

The use of ecomaterials in the construction of houses guarantees considerable energy savings in the production of construction elements, considering the growing housing deficit.

The reduction of environmental pollution through the use of ecomaterials in the life cycle of dwellings is achieved through the 


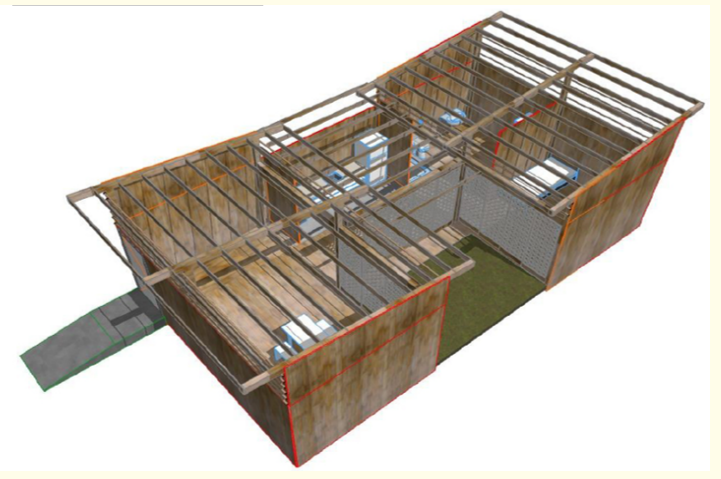

Figure 4: Rendering of the interior view of the archetype with the use of ecomaterials.

decrease in the generation of greenhouse gases as well as in the $\mathrm{CO}_{2}$ uptake resulting from the growth of plants.

The research carried out by the Multidisciplinary Group of Ecomaterials of the Institute of Habitat, Design and Construction of the Catholic University of Santiago de Guayaquil is aimed at guaranteeing a comfortable habitat for the inhabitants together with proposals that mitigate environmental pollution and rescue ancestral techniques in construction of residential spaces according to the region.

\section{Acknowledgements}

The authors would like to thank the School of Architecture and Design of the Catholic University of Santiago de Guayaquil, the workers of the Ecomaterial Production Plant and researchers of the Institute of Habitat, Design and Construction who have contributed in the production of ecological materials, especially Jorge Moran-Ubidia, is awarded the title, World Bamboo Pioneer by the World Bamboo Organization at the 1oth World Bamboo congress, Damyang-Korea 2015.

\section{Conflict of Interest}

There are no conflicts of interest.

\section{Bibliography}

1. Evangeliou, N., et al. "Open fires in Greenland in summer 2017: transport, deposition and radiative effects of $\mathrm{BC}, \mathrm{OC}$ and $\mathrm{BrC}$ emissions". Atmospheric Chemistry and Physics 19 (2019): 1393-1411.

2. Schlegel NJ., et al. "Exploration of Antarctic Ice Sheet 100-year contribution to sea level rise and associated model uncertainties using the ISSM framework". The Cryosphere 12 (2018): 3511-3534.

3. Blasco J., et al. "The Antarctic Ice Sheet response to glacial millennial-scale variability". Climate of the Past 15 (2019): 121133.

4. Forero B., et al. "Systemic Approach for Inclusive Design of Low-Income Dwellings in Popular Settlements at Guayaquil, Ecuador" (2019).
5. Fabbriani L and Calili R. "Proposal of energy efficiency policies for food and beverage industry in Brazil". Journal of Renewable and Sustainable Energy 10 (2018): 065903.

6. Dick S., et al. "Systemic Analysis of Bioclimatic Design of LowIncome State-Led Housing Program "Socio Vivienda" at Guayaquil, Ecuador" (2019).

7. Ricaurte V., et al. "Effects of the Urban Form on the External Thermal Comfort in Low-Income Settlements of Guayaquil, Ecuador" (2020).

8. Macas V., et al. "Gestión de la eficiencia energética en las edificaciones del Ecuador”. Opuntia Brava 10 (2019): 309-314.

9. Hechavarría J., et al. "Social Inclusion: A proposal from the University of Guayaquil to design popular housing with citizen participation" (2019).

10. Forero B., et al. "Bioclimatic Design Approach for Low-Income Dwelling at Monte Sinahí, Guayaquil” (2020).

11. Bamba JC and González AJ. "Prefabricando lo natural. los ecomateriales en la era de su reproductibilidad técnica. Ra". Revista de Arquitectura 20 (2018): 204-215.

Volume 3 Issue 11 November 2019

(c) All rights are reserved by Jesús Hechavarría. 